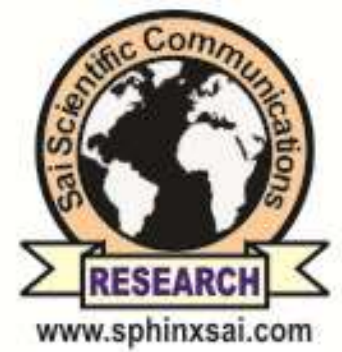

International Journal of PharmTech Research CODEN (USA): IJPRIF, ISSN: 0974-4304, ISSN(Online): 2455-9563 Vol.10, No.02, pp 69-73,

2017

\title{
Effect of Curcumin in Decreasing MDA Level in Preeclampsia-Induced Human Umbilical Vein Endothelial Cell (HUVEC)
}

\author{
Cut Meurah Yeni ${ }^{1 *}$, Prima Nanda Fauziah ${ }^{2}$, Ani Melani Maskoen ${ }^{3}$, \\ Rovina Ruslami ${ }^{4}$, Johannes Mose ${ }^{5}$
}

${ }^{1}$ Department of Obstetric and Gynecology, Faculty of Medicine, Universitas Syiah Kuala, Banda Aceh, Indonesia

${ }^{2}$ Department of Medical Laboratory Technology, School of Health Sciences Jenderal Achmad Yani, Cimahi, Indonesia

${ }^{3}$ Department of Oral Biology, Faculty of Dentistry, Universitas Padjadjaran, Bandung, Indonesia

${ }^{4}$ Department of Pharmacology and Therapy, Faculty of Medicine, Universitas Padjadjaran, Bandung, Indonesia

${ }^{5}$ Department of Obstetric and Gynecology, Faculty of Medicine, Universitas

Padjadjaran, Bandung, Indonesia

\begin{abstract}
Preeclampsia is multisystem disease occurred in 3-8\% pregnancy, indicated by hypertension and proteinuria after 20 weeks of gestational age. In preeclamptic patients, pro-oxidant decrease enzymatically in cell, followed by increase in lipid peroxida due to free radicals malondialdehyde (MDA). Elevated free radicals in preeclampsia is associated with reduced cellular antioxidants. Curcumin has been known to posses many biological activities, such as antiinflamation and antioxidants. We evaluated effects of curcumin on MDA level in preeclampia-induced HUVEC cell line. In the present study, we observed the effects of curcumin on MDA level in preeclampia-induced HUVEC cell line. MDA level was measured with Thiobarbituric Acid-reactive Substances (TBARS). The result of the present study showed curcumin decreased MDA level in preeclampsia-induced cell. Key words : curcumin, MDA, preeclampsia.
\end{abstract}

Introduction

Preeclampsia is multisystem disease occurred in 3-8\% pregnancy, indicated by hypertension and proteinuria after 20 weeks of gestational age. ${ }^{1,2}$ Preeclampsia causes both martenal and perinatal morbidity and mortality worldwide. ${ }^{1}$ Clinicial manifestasion of preeclampsia consists of hyperkoagulopati, hemolysis elevated liver enzyme and low platelets (HELLP), periportal hemorrhage in liver, ischemic lesion, fibrin cumualtion, subcapsular hemorrhage and intrahepatic hematoma or even hepatic rupture, acute renal failure and segmental glomeruloskeloris segmental. ${ }^{1-3}$ Moreover, preeclampsia causes cramp (eclampsia), headache, blurry vision, scotoma or even blidness, cerebral hemorrhage, brain damage due to ischemia or microinfark and fibrinoid necrosis in brain. ${ }^{2,3}$ 
Pathogenesis of preeclampsia remains unclear. Placenta is believed to play the key role. ${ }^{5}$ Placenta is a source and central of any mediators in preeclampsia pathogenesis. ${ }^{6,7}$ Morever, placenta is also responsible in preeclampsia development, in which there is disturbance in placentation, poor invasion, and abnormal angiogenesis which is the main pathological manifestation. ${ }^{7}$ These events are results from oxidative stress found in placenta in preeclampsia. Studies show that soluble vascular endothelial growth factor receptor-1 (VEGFR1) or known as soluble fms-like tyrosine kinase-1 (sFlt-1) and soluble endoglin (sEng), are mediator mechanism between ischemic placenta and oxidative stress with failure in local angiogenesis ${ }^{8,9}$, that leads to systemic vascular dysfunction. ${ }^{10}$ Oxidative strees can also stimulate release of cytokines, antiangiogenics, microparticles and other essential molecules in preeclampsia. ${ }^{11}$ Antiangiogenic plays role in early development of placental vascular and during trophoblast invasion, and hypoxia is the major regulator on its expression. ${ }^{10}$ Previous studies show that oxidative stress induced sflt- 1 concentraion. ${ }^{11}$ Elevated sflt- 1 caused reduction in placental growth factor (PIGF) and vascular endothelial growth (VEG) signaling.

Oxidative stress is caused by imbalance of pro-oxidant and antioxidant. In preeclamptic patients, prooxidant decrease enzymatically in cell, followed by increase in lipid peroxida due to free radicals malondialdehyde (MDA). Furthermore, increase lipid peroxida leads to disturbance in cell integrity, uncontrolled lipid peroxida both in cell and tissues that promotes lysis of cell membrane and edhotels, vascular reactivation, and increase vascular permeability due to activation of neutrophil estalase. Neutrophil estalase can be used as marker in endothelial dysfunction on molecular level. In preeclampsia, MDA is present in plasma, small blood vessels, and desidua basalis. ${ }^{12,13}$

Elevated free radicals in preeclampsia is associated with reduced cellular antioxidants. Curcumin is a compound found in Curcuma longa ${ }^{14}$ Curcumin has been known to posses many biological activities, such as antiinflamation and antioxidants. ${ }^{15}$ Thus, curcumin is considered as a potent approach in treating oxidative stress and inflammation-related diseases. ${ }^{15}{ }^{16} \mathrm{Hansson}$, Chen ${ }^{17}$ proposed that curcumin can be utilized as alternative therapy for preeclampsia due to its ability in inhibiting regulator protein, as well as NFkB. Recent study found that curcumin reduced MDA level, as well as NFkB expression in preeclamptic rats. ${ }^{18}$ In the present study, we observed the effects of curcumin on MDA level in preeclampia-induced HUVEC cell line.

\section{Materials and Method}

Samples used were women at 32-42 weeks of gestational age which were diagnosed preeclampsia and normal pregnancy at the same gestational age from Dr. Hasan Sadikin General Hospital, Indonesia. Research subjects has fulfilled inclusion and exclusion criteria.

\section{Cell culture}

HUVEC cell line was grown in tissue culture flask $\left(25 \mathrm{~cm}^{2}\right)$ containing RPMI 1640 supplemented with $10 \%$ (v/v) FBS qualified (fetal bovine serum), antibiotic-anti-micotic 1\% Penicillin G-Streptomycin Solution Stabilised dan (1\% Fungizone Amphotericin B) and $1 \%$ gentamisin, then incubated at $37^{\circ} \mathrm{C}$ atmosphere 5\% (v/v) $\mathrm{CO}_{2}$. Medium was replaced 2-3 times a day. Cell were the checked every 7 days or untill $90 \%$. confluent ${ }^{131}$ Cells viability was measured with trypan blue on haemocytometer under light microscope with 400x magnification. ${ }^{19-21}$

\section{Measurement of MDA level}

Cells of $6 \times 10^{5} \mathrm{cell} / \mathrm{ml}$ induced with both normal and preeclampsia serum, were placed into 96 -well plate, then incubated at $37^{\circ} \mathrm{C} 5 \% \mathrm{CO}_{2}(\mathrm{v} / \mathrm{v})$. Furthermore, each wells were washed 3-4 times with $\mathrm{PBS} 37^{\circ} \mathrm{C}$. Various concentrations of curcumin $(0 ; 0,977 ; 1,953 ; 3,906 ; 7,813 ; 15,625 ; 31,25 ; 62,5 ; 125 ; 250 \mu \mathrm{g} / \mathrm{ml})$ were then distributed to each well, incubated for 24 and 48 hours $37^{\circ} \mathrm{C} 5 \% \mathrm{CO}_{2}(\mathrm{v} / \mathrm{v})$. Each well was washed with PBS pH 7,4 once for 5 minute, and then centrifuged for 20 minute at $3.000 \mathrm{rpm}$. Supernatants were carried for measurement of MDA level with Thiobarbituric Acid-reactive Substances (TBARS). Cells were given solution containing $15 \% \mathrm{w} / \mathrm{v}$ trichloroacetic acid, $0,375 \mathrm{w} / \mathrm{v}$ thiobarbituric acid, $0.25 \%$ hydrichloric acid and $0.2 \%$ triton $X$. Samples were then suspended with heating at $100^{\circ} \mathrm{C}$ for 15 minutes, then centrifuged at $4500 \mathrm{rpm}$ for $10 \mathrm{~min}$. Absorbance was read at $532 \mathrm{~nm}$ wavelength. ${ }^{20,21}$ 


\section{Data analysis}

Data was analyzed with T-test if normally distributed, and Mann Whitney test if not normally distributed. Data was quantitavely analyzed with ANOVA DMRT (Duncans's Multiple Range Test) to determine the significance among variables in each treatment SPSS 14.

\section{Results and Discussion}

\section{MDA levels}

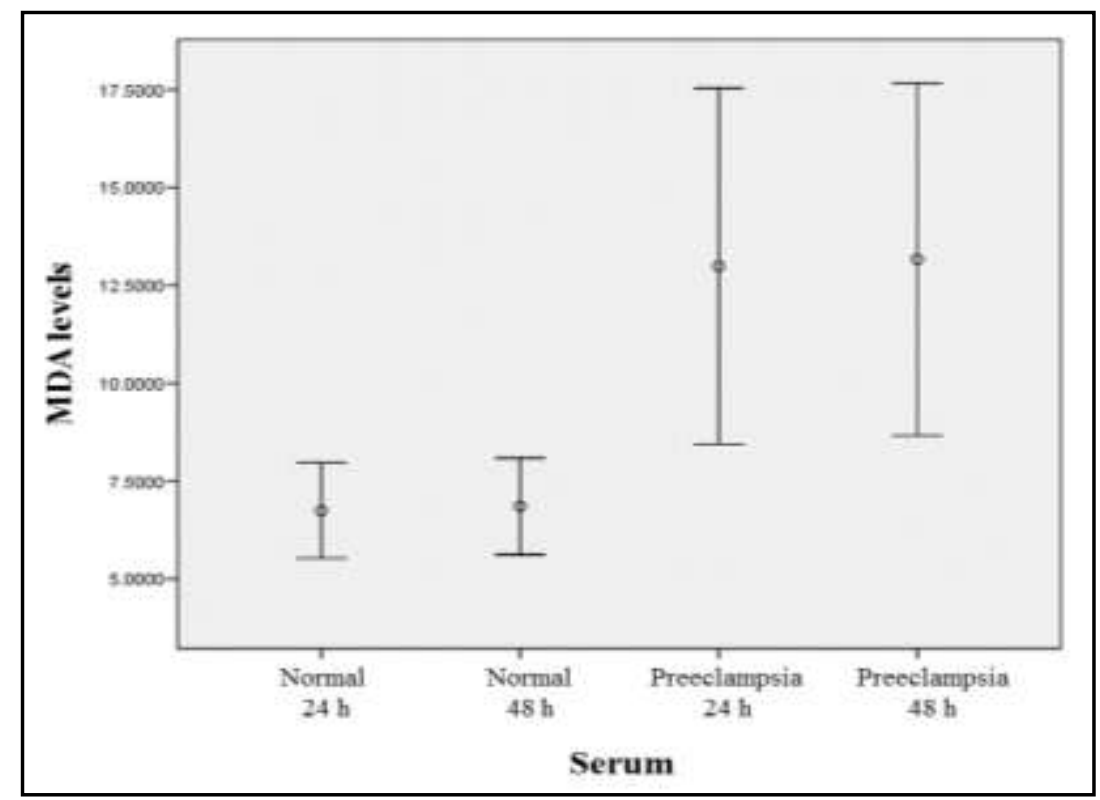

Figure 1. Effects of curcumin in various concentrations and incubation time on level of MDA

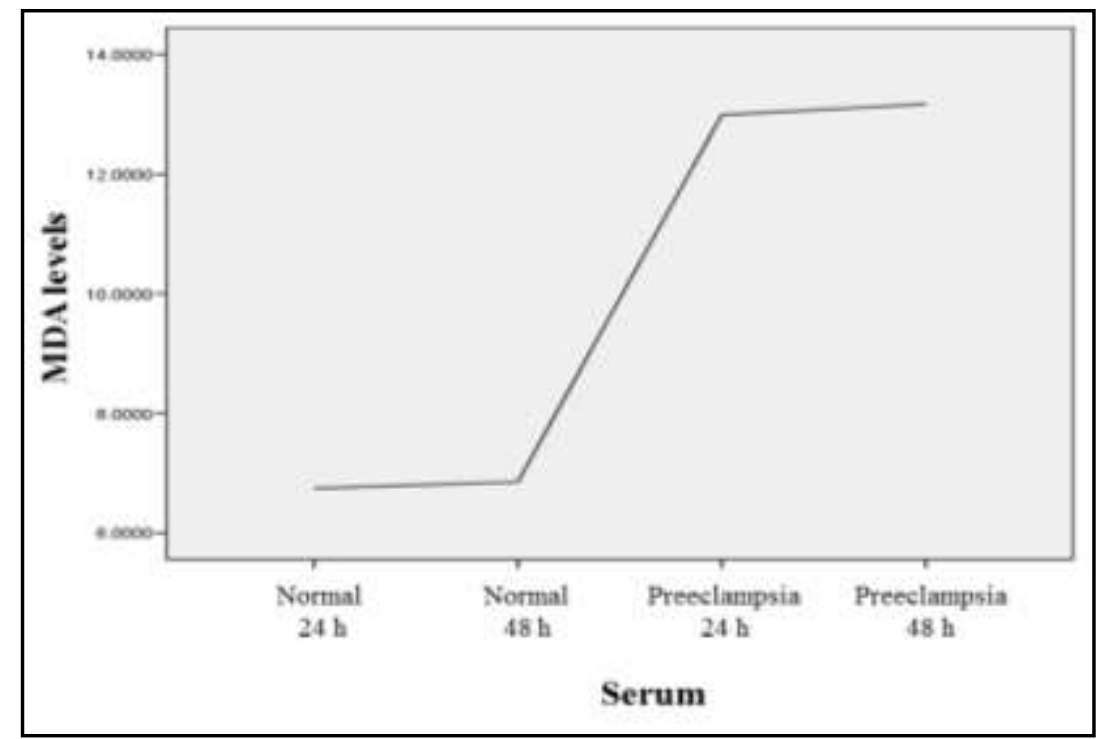

Figure 2. Ratio of MDA levels in preeclampsia-induced HUVEC based on incubation times and curcumin concentration

As shown in Figure 1, MDA level and treatment of curcumin in control and cell, was the highest among treatments. Treatment of curcumin showed effect both in normal and preeclampsia serum after $24 \mathrm{~h}$ nd $48 \mathrm{~h}$ incubation. 
Variables tested in this study were normally distributed both in normal and preeclampsia serum treated with curcumin in various concentrations incubated for $24 \mathrm{~h}$ and $48 \mathrm{~h}$ (data are not shown). Effects of curcumin in various concentration, incubation time, and serums on level of MDA are presented in Figure 2. As shown in Figure 2, level of MDA decreased as in accordance with longer incubation time and increased curcumin concentration. Curcumin decreased level of MDA $(\mathrm{p}<0,001)$. Level of MDA in preeclampsia-induced HUVEC decreased from $18,703 \mu \mathrm{M}$ to $8,577 \mu \mathrm{M}$ after treated with curcumin of $62,5 \mu \mathrm{g} / \mathrm{ml}$ incubated for $24 \mathrm{~h}$, and higher after $48 \mathrm{~h}$ from $18,872 \mu \mathrm{M}$ to $8,667 \mu \mathrm{M}$.

\section{Discussion}

Oxidative stress is caused by imbalance of pro-oxidant and antioxidant. In preeclamptic patients, prooxidant decrease enzymatically in cell, followed by increase in lipid peroxida due to free radicals malondialdehyde (MDA). Furthermore, increase lipid peroxida leads to disturbance in cell integrity, uncontrolled lipid peroxida both in cell and tissues that promotes lysis of cell membrane and edhotels, vascular reactivation, and increase vascular permeability due to activation of neutrophil estalase. Neutrophil estalase can be used as marker in endothelial dysfunction on molecular level. In preeclampsia, MDA is present in plasma, small blood vessels, and desidua basalis. ${ }^{12,13}$

Elevated free radicals in preeclampsia is associated with reduced cellular antioxidants. In the present study, curcumin decreased MDA level in preeclampsia-induced cell. This result is supported by previous study that curcumin significantly attenuated MDA level and recovered the GSH and SOD levels. ${ }^{22}$ Curcumin is known to protect biomembranes against peroxidative damage. Peroxidation of lipids is known to be a freeradical-mediated chain reaction, leading to the damage of the cell membranes, and the inhibition of peroxidation by curcumin is mainly attributed to the scavenging of the reactive free radicals involved in the peroxidation. Most of the antioxidants have either a phenolic functional group or a -diketone group. Curcumin is an unique antioxidant, which contains a variety of functional groups, including the B-diketo group, carbon-carbon double bonds, and phenyl rings containing varying amounts of hydroxyl and methoxy substituents. ${ }^{23}$

Curcumin has been studied recently in treatment of preeclampsia. Curcumin treatment in various doses could decrease significantly pro-inflammatory cytokines levels in preeclamptic plasma-induced. After curcumin treatment, there was decreased level of nuclear NF-kB p50 and increased level of PPAR- $\%$ significantly. ${ }^{24}$ In other study, LPS-curcumin-treated group had decreased blood pressure and urinary protein level, which was comparable to control group, as well as improved trophoblast invasion and spiral artery remodeling induced by LPS. Increased TLR4, NF-kB and IL-6, MCP-1 protein expressions in LPS-treated group were significantly decreased after curcumin administration. ${ }^{25}$

\section{References}

1. L. Duley, Semin. Perinatol., 33, 130 (2009); doi:10.1053/j.semperi.2009.02.010.

2. B. Sibai, G. Dekker and M. Kupferminc, Lancet, 365, 785 (2005); doi:10.1016/S0140-6736(05)710035 .

3. S. Baumwell and S.A. Karumanchi, Nephron Clin. Pract., 106, c72 (2007); doi:10.1159/000101801.

4. S. Tenhola, E. Rahiala, P. Halonen, E. Vanninen and R. Voutilainen, Pediatr. Res., 59, 320 (2006); doi:10.1203/01.pdr.0000196734.54473.e3.

5. L. Myatt, Endocrine, 19, 103 (2002); doi:10.1385/ENDO:19:1:103.

6. $\quad$ B. Huppertz, Hypertension, 51, 970 (2008); doi:10.1161/HYPERTENSIONAHA.107.107607.

7. F. Broughton Pipkin and J.M. Roberts, J. Hum. Hypertens., 14, 705 (2000); doi:10.1038/sj.jhh.1001018.

8. R.J. Levine, C. Lam, C. Qian, K.F. Yu, S.E. Maynard, B.P. Sachs, B.M. Sibai, F.H. Epstein, R. Romero, R. Thadhani and S.A. Karumanchi, N. Engl. J. Med., 355, 992 (2006); doi:10.1056/NEJMoa055352.

9. F. Lu, M. Longo, E. Tamayo, W. Maner, A. Al-Hendy, G.D. Anderson, G.D.V. Hankins and G.R. Saade, Am. J. Obstet. Gynecol., 196, 396e1 (2007); doi:10.1016/j.ajog.2006.12.024.

10. B.C. Young, R.J. Levine and S.A. Karumanchi, Annu. Rev. Pathol., 5, 173 (2010); doi:10.1146/annurev-pathol-121808-102149.

11. A. Wang, S. Rana and S.A. Karumanchi, Physiology (Bethesda), 24, 147 (2009); doi:10.1152/physiol.00043.2008.

12. A. Rajakumar and K.P. Conrad, Biol. Reprod., 63, 559 (2000); doi:10.1095/biolreprod63.2.559. 
13. R.A. Irani, Y. Zhang, S.C. Blackwell, C.C. Zhou, S.M. Ramin, R.E. Kellems and Y. Xia, J. Exp. Med., 206, 2809 (2009); doi:10.1084/jem.20090872.

14. FAO. Curcumin- chemical and technical assessment 61st JECFA 2004.

15. I. Chattopadhyay, K. Biswas, U. Bandyopadhyay and J.K. Banerjee, Curr. Sci., 1, 44 (2004).

16. J.S. Jurenka, Altern. Med. Rev., 14, 141 (2009).

17. S.R. Hansson, Y. Chen, J. Brodszki, M. Chen, E. Hernandez-Andrade, J.M. Inman, O.A. Kozhich, I. Larsson, K. Marsál, P. Medstrand, C.C. Xiang and M.J. Brownstein, Mol. Hum. Reprod., 12, 169 (2006); doi:10.1093/molehr/gal011.

18. D. Subroto, Curcumin decrease placental NF- $\mathrm{KB}$ expression and malonedialdehide serum in preeclamptic Mus musculus model. Surabaya: Universitas Airlangga; 2011.

19. C. Munaut, S. Lorquet, C. Pequeux, S. Blacher, S. Berndt, F. Frankenne and J.-M. Foidart, Hum. Reprod., 23, 1407 (2008); doi:10.1093/humrep/den114.

20. A.Y. Pramatirta, B. Laksono, N.F. Prima, D.A. Anita, R.K. Sofie, S.R. Debbie, M.M. Ani and W. Erlina, Int. J. Pharm. Tech. Res., 9, 1 (2016).

21. Gunardi, J.I., Mose, J., Mieke, H.S., Anita, D.A., Prima, N.F., and Triyuli, Int. J. PharmTech. Res., 9, 424 (2016).

22. X.H. Wan, Y.W. Li and X.P. Luo, Zhonghua Er Ke Za Zhi, 45, 604 (2007).

23. J.S. Wright, J. Mol. Struct. THEOCHEM, 591, 207 (2002); doi:10.1016/S0166-1280(02)00242-7.

24. B. Rahardjo, E. Widjajanto, H. Sujuti and K. Keman, Biomarkers Genomic Medicine, 6, 105 (2014); doi:10.1016/j.bgm.2014.06.002.

25. P. Gong, M. Liu, G. Hong, Y. Li, P. Xue, M. Zheng, M. Wu, L. Shen, M. Yang, Z. Diao and Y. Hu, Placenta, 41, 45 (2016); doi:10.1016/j.placenta.2016.03.002. 